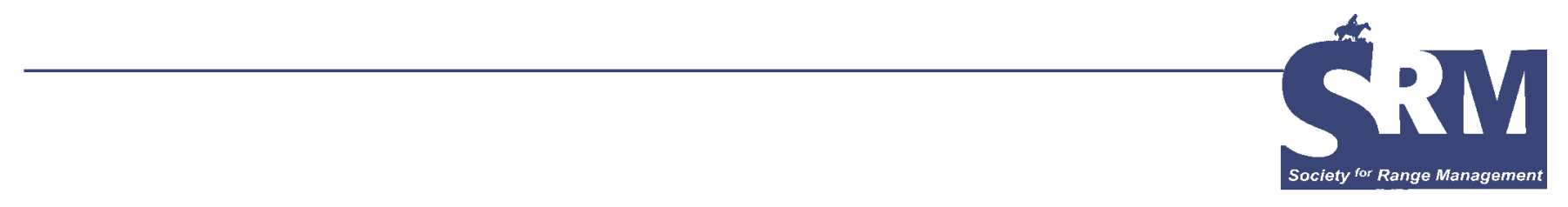

\title{
Contributing to the Mitigation of Climate Change Using Rangeland Management
}

\section{By J. E. de Steiguer, Joel R. Brown, and Jim Thorpe}

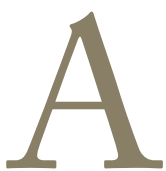

rational approach to responding to the uncertainty of climate change requires attention to both mitigation and adaptation activities. Mitigation, in contrast to adaptation, involves the reduction of greenhouse gas emissions and enhancement of greenhouse gas sinks. ${ }^{1}$ The goal of mitigation is to stabilize atmospheric greenhouse gas concentrations at a level that would prevent human interference with the natural climate system. ${ }^{1}$ Several methods for reducing emissions have been suggested for various sectors of the global economy (Table 1). These include increased energy efficiency, the use renewable energy sources such as solar and wind, the use of biofuels and hybrid energy vehicles, recycling, greater use of public transportation, improved land use planning, and management of methane emissions. Most credible analyses of the range of actions necessary to meet society's energy needs while lowering greenhouse gas emissions include the use of both emission reduction and sequestration technologies and practices.

The sequestration technology that has garnered the most attention, based on capacity, is geologic sequestration, extracting carbon dioxide $\left(\mathrm{CO}_{2}\right)$ from the atmosphere and storing it in geologic formations for long periods of time $(>1,000 \mathrm{yr})$. Although geologic sequestration offers great potential, many of the necessary technologies are unproven or not currently cost effective. Other sequestration technologies, such as ocean fertilization, have potential environmental downsides. Terrestrial sinks, on the other hand, are viable with current technology and are largely environmentally neutral or beneficial. ${ }^{2}$ Natural terrestrial carbon sinks can be enhanced by practices and activities that increase carbon storage carbon and include improved cropland and rangeland management, reforestation, and reduced deforestation.
Both emission reduction and sink enhancement mitigation measures are being initiated at city, state, regional, and global levels through both voluntary actions ${ }^{3}$ in the private sector and as a result of national laws and policies such as those passed by the US Congress. ${ }^{4}$ Many public policy and business analysts confidently predict a hybrid approach that will integrate government-mandated and -supported emission reduction strategy and a private sector market to discover the most cost-effective means of meeting targets.

\section{Market-Based Mitigation}

Both legally mandated compliance efforts and voluntary offsets have increasingly relied upon market-based methods of implementation. Market-based methods utilize property rights, prices, and free markets, and, thereby, attempt to spark innovation and generate cost savings while lowering greenhouse gas emissions. They stand in contrast to more traditional command-and-control mitigation approach where both targets and methods of achieving them are mandated (e.g., best management practice for water quality improvement). Market-based approaches have their foundation in the theoretical economics literature, but they also have been applied in the real world with considerable success. ${ }^{4}$ The value of greenhouse gas mitigation market transactions has increased rapidly in recent years and, in 2006, totaled $\$ 30$ billion. $^{3}$

Market-based mitigation methods can be separated into two categories: allowance-based transactions and projectbased transactions with the former being more prevalent. ${ }^{3}$ Of the total transaction value of $\$ 30$ billion, $88 \%$ has been for allowance transactions, whereas $12 \%$ has been for project-based transactions. 
Table 1. Key mitigation technologies and practices by economic sector

Economic sector

Energy supply

Transportation

Buildings

Industry

Agriculture

Forestry

Waste management

\section{Mitigation technologies and practices currently available}

Improved energy efficiency, alternative energy, renewables, carbon dioxide capture, storage

Improved energy efficiency, hybrid vehicles, biofuels, switch to public transport, land-use planning

Improved energy efficiency, improved climatization and lighting, solar design

Improved energy efficiency, recycling, heat and power recovery

Improved crop and grazing management to improve soil carbon storage, management of methane emissions, improved fertilizer use, improved energy efficiency

Afforestation, reforestation, reduced deforestation, bioenergy

Methane recovery, energy recovery, recycling

Adapted from Intergovernmental Panel on Climate Change 2007, ${ }^{1}$ p. 10.
Allowance transactions, also known as cap-and-trade arrangements, set a national or regional upper limit (i.e., a "cap") on greenhouse gas emissions and then allocates the cap among the individual emitting entities. Firms that are under their annual permissible emission levels can sell excess allowances to companies that have exceeded their emission allowances. Such trades can be made company-to-company or through approved commercial brokerage houses. Capand-trade schemes, supporters say, combine environmental performance, as defined by the cap itself, and flexibility that allows participants to be in compliance at the lowest possible cost. The most well-known cap-and-trade arrangement is found in the Kyoto Protocol, but there are other efforts around the world as well. The idea of establishing projects on one part of the globe to sequester greenhouse gas emitted in another part makes sense because of the global nature of the climate change problem.

Project-based arrangements are those in which a greenhouse gas-emitting entity offsets its excess emissions by purchasing credits from a project that has been created expressly for that purpose. Such projects can serve either the compliance or the voluntary offsets market. The most notable examples of compliance market project-based arrangements are the Clean Development Mechanisms and Joint Implementation of the Kyoto Protocol. Clean Development Mechanisms are projects implemented by a developed nation in a developing nation, whereas Joint Implementation are projects between two developed nations. Voluntary market projects can be found worldwide, and are rapidly increasing in number. Investment in Kyotorelated projects (Fig. 1) provides some indication of the relative popularity of various types of mitigation projects. Interesting to note is the relatively small size (i.e., $1 \%$ of total value) of the agro-forestry projects.

The viability of an individual sequestration project is largely a function of the cost of achieving that mitigation. Once in the marketplace, a ton of carbon has an established value, regardless of the source of the reduction (emission

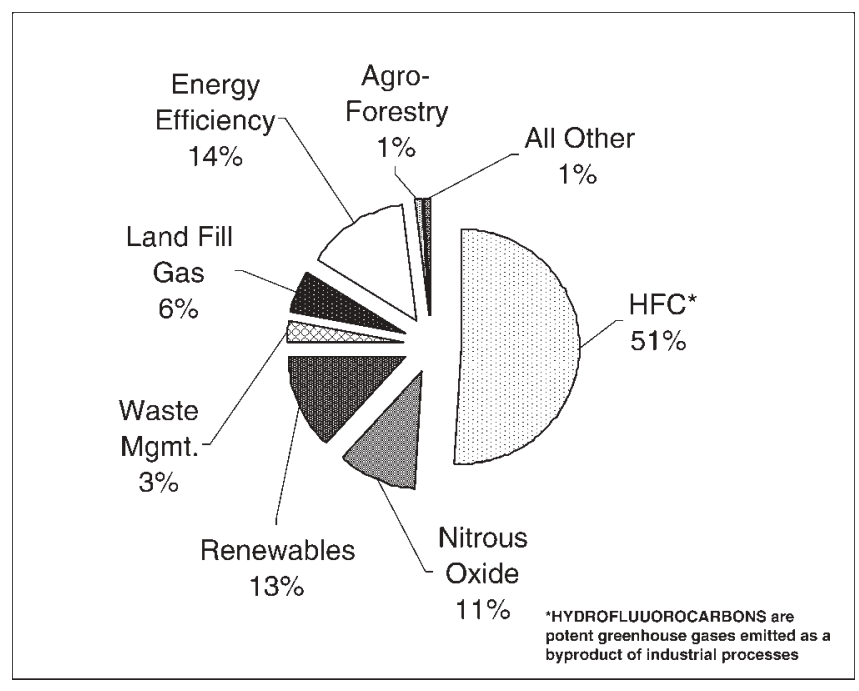

Figure 1. Relative value of Kyoto mitigation projects (2006-September 2007; source: Intergovernmental Panel on Climate Change).

reduction or sequestration). So the viability of a project depends on the ability of organizers to optimize the difference between costs of implementation and the price of carbon in the market. Such costs can either be direct cash outlays (such as for grass seed or fencing to restore degraded land), opportunity costs of diverting land from other revenue-producing activities (such as conversions of marginal cropland to perennial grass), or the costs of implementing sequestering management practices. Hence, sequestration based mitigation is essentially a question of economics. ${ }^{5}$ If a project is to be successfully organized and traded in the carbon offsets market, its cost per ton of sequestering carbon (including all overheads and transaction costs) must be lower than prices offered in the market. These "indirect" costs can represent a substantial proportion of potential rangeland projects. Controlling them requires a well-developed understanding of both the ecology of rangelands and extensive knowledge of their management. 


\section{Rangeland Carbon Credits}

The full spectrum of range management activities gives rise to a variety of possible offset projects. For example, projects to reduce fossil fuel consumption operation-wide or to reduce enteric methane emissions are two possibilities. However, we will focus on offset projects directly related to the management of land and to soil carbon storage. Follett et al. $^{6}$ have provided a recent summary of research on the physical carbon storage potential of rangelands. Based on the available research, they estimate a variety of relatively common rangeland management practices can sequester between 130 and 300 million metric tons of $\mathrm{CO}_{2}$ equivalents $\left(\mathrm{MMTCO}_{2} \mathrm{e}\right)$ per year. In addition, they suggested two important points that are relevant to rangeland carbon sequestration: 1) rangeland soils are extremely heterogeneous and carbon content is difficult to measure with statistical accuracy, and 2) any significant gains in carbon storage would require changes in existing rangeland management. ${ }^{7}$

Determining the potential and actual changes in carbon storage on rangeland soils is complex and the synthesis of the relatively few experimental or comparative studies rarely provides unambiguous results. Carbon fluxes on rangelands are driven by several interacting factors such as precipitation, temperature, and inherent soil and vegetation properties. Even commonly used and well-understood management practices such a grazing and burning can have either negative or positive effects on soil carbon, depending on initial conditions, implementation protocols, and postimplementation environmental conditions. ${ }^{8}$ Although rangeland research studies have been helpful in gaining a general understanding of carbon dynamics, a site-specific predictive model is not yet available.

Accounting for, and managing, the uncertainty inherent in rangeland ecosystem and projects will likely be the major determinant in developing cost effective sequestration projects. Unfortunately, the number of rangeland offsets economic studies is considerably fewer than for cropland and forestry. However, the offset potential of private grazing lands in the United States was recently examined. ${ }^{8}$ Those authors noted that there are some 254 million acres (100 million ha) of private grazing lands in the United States with the potential to store an additional 60 million tons of carbon $\left(220 \mathrm{MTCO}_{2} \mathrm{e}\right)$ per year. Their study examined the costs of creating offset credits on a 40,000-acre cow/calf operation in Wyoming through a variety of practices: alfalfa interseeding, summer movement of cattle from sensitive grazing areas, sagebrush thinning, and fencing. The results indicated that, over a 20-yr period, carbon credits could be produced at a cost of between $\$ 8$ and $\$ 17$ per $\mathrm{MTCO}_{2} \mathrm{e}$. Based upon these results, the authors concluded that this particular private ranch could compete favorably against cropland and forestland for the sale of carbon credits.

Another recent study examined the cost of sequestering carbon on semiarid state-owned rangelands in Arizona. ${ }^{5}$
The study assumed, purely hypothetically, that Arizona state government contemplated selling credits from carbon offset projects on their trust lands. The underlying notion was that reduced stocking rates of cattle grazing on state rangelands would increase soil carbon. This idea was tested by simulating range management conditions for 12 different soil profiles. In many instances the semiarid rangeland sequestration costs were less than, hence competitive with, current carbon credit trading prices. Thus, some semiarid rangeland soils might be candidates for carbon offsets management that would provide new economic opportunities. However, the study also noted that the dedication of semiarid state and federal lands to carbon sequestration at the expense of cattle grazing raises some equity and local economic viability issues that must be dealt with through the political system.

\section{Rangeland Carbon Offsets}

The Chicago Climate Exchange (CCX), North America's only voluntary, legally-binding trading system, manages what is now the world's largest rangeland soil carbon offset program. ${ }^{9}$ The CCX requires from rangeland project managers a minimum 5-yr contractual commitment. Both nondegraded rangelands and previously degraded rangelands are eligible to be considered for carbon sequestration projects using improved grazing management practices: light to moderate stocking rates, appropriate distribution, proper season of use, and rapid drought response. Projects from six designated land resource regions within the western United States are considered. Qualifying projects receive offset credits based not on actual carbon soil accumulations, but at standardized default rates varying from 0.12 to 0.52 metric tons of carbon dioxide per acre per year, depending on project type and location. At least once per year, an independent CCX-authorized verifier conducts in-field inspections to ensure that rangeland management practices are in accordance with contracts. Among the information collected during verification are site photographs, ranch rainfall and stocking records, and occasionally data available from institutional sources (rainfall, productivity measurements, etc).

In order to address failures to maintain the contracted management practices or occurrence of drought, each year $20 \%$ of the contractually accumulated carbon is placed into a special reserve account. CCX then cancels in the reserve account a tonnage amount equal to the losses resulting from the failed contracts and/or drought. Any project owner who fails to conform to the practices specified in their CCX contract is banned from future participation. Small offset projects, i.e., those involving less than 10,000 metric tons of carbon dioxide per year, are combined through an agent known as an Offset Aggregator to form a larger trading unit. Recent CCX offset credit prices, which are among the lowest in the world, have ranged from below $\$ 1$ to above \$5 per TCO2e. Daily trade volumes in 2007 averaged in excess of 100,000 metric tons of carbon dioxide. 


\section{Some Implementation Barriers}

Within the ranching community, the prospect of being able to market an "ecological service" such as rangeland soil carbon sequestration, has been met with a mixed reception. ${ }^{i}$ While on the one hand the opportunity for a new source of revenue, one that implicitly rewards superior and sustainable range management, is welcome, there is considerable mystification at being able to sell an essentially intangible product, and concern about potentially intrusive obligations and unforeseen liabilities. In addition, the sociopolitical divide that pervades every aspect of global climate change is apparent in the rangeland carbon market. Many conservative-leaning ranchers question the motivations behind the visibility of the issue of climate change, much less the need to act to prevent it.

Thus, the early participants in rangeland carbon offset projects might need to overcome some social and philosophical considerations as well as many practical concerns and apprehensions. As in any new market, there is some feeling that traders are "making it up as they go along." The legal templates and boilerplate contracts are similar to other access rights and services agreements, such as energy exploration and development leases, and often do not address landowner concerns. As in other commodity markets, there is a feeling that the traders, speculators, and the middlemen will be the ones in position to make "the real money," and there is legitimate concern about unanticipated liabilities for nonperformance, especially in the event of drought.

Although eligibility regions and crediting rates are relatively simple and straightforward to interpret in an attempt to manage overhead costs, ranchers have also expressed concern and confusion about eligibility requirements, prescribed practices, and verification protocols. They are keenly aware of the heterogeneity of their rangeland landscapes (soils and plant communities) and the often extreme temporal and spatial variability in precipitation and primary production that drive sequestration. The core premise of the rangeland carbon program is that additional carbon will be stored through improved management, but many ranchers, especially those who by all accounts have always been superior managers (sometimes for generations), wonder what are they going to do differently that will significantly increase their incremental carbon storage. Will they, they wonder, be thus unable to participate and be essentially penalized for their past superior practice?

The status of the large acreages of federal and state lands, in terms of their carbon storage potential, and the role that lease-holder management might play in this, is of considerable interest. Of particular concern is the interaction of already contentious stocking rates, drought response, and carbon sequestration rates. Some states, such as New Mexico, have joined the CCX, thereby enabling arrangements to

'The following comments are from personal observations and communications with ranchers by the authors. allow qualified holders of New Mexico State Trust Lands grazing leases to enroll these lands as part of their private soil carbon projects; the revenue is to be shared in a similar manner (two-thirds to the managing lease-holder, one-third to the state land trust) to which some leases have previously been enrolled in Conservation Reserve Program contracts. Such "stewardship across boundaries" is an example of the cooperative approaches involving private and public rangelands, which could significantly contribute to the future health and well-being of both.

Finally, ranchers are confused about what levels of record keeping, documentation, and monitoring will be required for compliance. Generally not welcoming of any detailed inquiry from "outside" (as during the visits of the "verifiers," presumably persons with some knowledge of rangeland practice and cultural protocols), ranchers are concerned about the privacy of their "proprietary information" (lest it somehow, someday be used against them), and of losing the flexibility of their own tried and true versions of "adaptive management" in the face of having to follow a promulgated plan involving "grazing land management that employs sustainable stocking rates, rotational grazing, and seasonal use in eligible locations" that, according to one aggregator, "must meet or exceed USDA standards."

Such concerns will most likely subside as more ranchers enroll and rangeland carbon offset contracts become less novel. By working first through the aggregators, who among other things essentially act as an initial interface that orients and prequalifies rancher applicants, many of the ranchers' concerns are addressed up front. According to one aggregator, "We ask for proof of seasonal use or rotational grazing, documentation that the stocking rate does not exceed the sustainable rate, documentation that the landowner has a drought mitigation plan, has followed their turn in or turn out dates, and samples of their monitoring system. As an aggregator we make the first call that the system meets the CCX standards, with the final call by the verifier." ${ }^{\mathrm{ii}}$

\section{Summary}

Despite these concerns, as well as those from a significant proportion of the environmental community, the mitigation of climate change through projects, such as those occurring on rangelands, seems to have momentum. The market for carbon credits has grown rapidly within the recent years and has been projected to exceed $\$ 500$ billion in trades by $2020 .^{10}$ This developing situation certainly warrants watching by rangeland interests. Rising carbon credit prices would certainly make investments in rangeland mitigation projects a financially attractive, and an environmentally proactive, alternative to traditional land management. However, as a relatively small portion of any potential private sector carbon market, terrestrial sequestration in general, and rangelands in particular, must operate efficiently within the market

\footnotetext{
ii Ted Dodge, President, National Carbon Offset Coalition.
} 
(prices and rules) and exploit inherent competitive advantages. Rangeland carbon sequestration projects are competitive because of the relatively low cost of achieving increased soil carbon storage and its compatibility with existing management operations and production systems. On the other hand, documenting and verifying changes in carbon storage is a daunting challenge. The success of rangeland projects as participants in a private sector market will be determined in large part by the ability of the rangeland management profession (scientists, advisors, and managers) to develop accurate, credible, and cost-effective protocols to ensure to both buyers and the public that gains are real.

\section{References}

1. Intergonernmental Panel on Climate Change. 2007. Climate change 2007: mitigation. In: B. Metz, O. R. Davidson, P. R. Bosch, R. Dave, and L. A. Meyer [EDs.]. Contribution of Working Group III to the Fourth Assessment Report of the Intergovernmental Panel on Climate Change. Summary for Policymakers, 24 p. Cambridge, United Kingdom: Cambridge University Press. p. 818.

2. Pacala, S., And R. Socolow. 2004. Stabilization wedges: solving the climate problem for the next 50 years with current technologies. Science 305:968-972.

3. Capoor, K., and P. Ambrosi. 2007. State and trends of the carbon market, 2007. Washington, DC, USA: The World Bank. 45 p.

4. Tietenberg, T. 2002. The tradable permits approach to protecting the commons: what have we learned? In: E. Ostrom et al. [EDS.]. The drama of the commons. Washington, DC, USA: The National Academies Press. p. 197-232.
5. De Steiguer, J. E. 2008. Semiarid rangelands and carbon offset markets: a look at the economic prospects. Rangelands 30(2):27-32.

6. Follett, R. F., J. M. Kimble, and R. Lal [eds.]. 2001. The potential of U.S. grazing lands to sequester carbon and mitigate the greenhouse effect. Boca Raton, FL, USA: Lewis Publishers. $442 \mathrm{p}$.

7. Sobecki, T. M., D. L. Moffitt, J. Stone, C. D. Franks, and A. G. Mendenhall. 2001. Chapter 2, the broad-scale perspective on the extent, distribution and characteristics of U.S. grazing lands. In: R. F. Follett, J. M. Kimble, and R. Lal [EDs.]. The potential of U.S. grazing lands to sequester carbon and mitigate the greenhouse effect. Boca Raton, FL, USA: Lewis Publishers. p. 21-63.

8. Campbell, S., S. Mooney, J. P. Hewlett, D. J. Menkhaus, And G. F. VAnce. 2004. Can ranchers slow climate change? Rangelands 26(4):16-22.

9. CCX Rangelands Carbon Offrets. Available at: http:// www.chicagoclimatex.com/content.jsf?id=1101. Accessed 12 December 2007.

10. Baker-SAid, S. 2007. Carbon game: cheap credits in $\mathrm{CO}_{2}$ are for sale in Europe. Bloomberg News, printed in The Arizona Daily Star 12 November:D4.

Authors are Professor, School of Natural Resources, University of Arizona, jedes@Ag.arizona.edu (de Steiguer); Rangeland Scientist, USDA-NRCS, Jornada Experimental Rangem MSC 3JER, PO Box 30003, New Mexico State University, Las Cruces, NM 88003-0003, USA (Brown); and Rancher, JT Land and Cattle LLC and CCX rangeland carbon project participant, Nerwkirk, NM 88431, USA (Thorpe). 